\title{
Models of Information Markets: Analysis of markets, identification of services, and design models
}

\author{
Fons Wijnhoven \\ University of Twente The Netherlands
}

a.b.j.m.wijnhoven@sms.utwente.n

\begin{abstract}
The Internet reduces much of the costs of information sharing, but it does not solve information receivers' reading and interpretation limitations. Browsers and navigators ease information retrieval but do not solve the problems of specifying information needs and evaluating retrieval results. This article approaches these problems as information market problems with solutions consisting of information market service process models. These models link information suppliers and buyers and define activities, information resources, and information flows for the information market services. The models identified may improve the quality, speed, design and realisation of information market services.
\end{abstract}

Keywords: Internet, information market, semantics, information good, information service models

\section{Introduction \& Research Problem}

The use of the Internet for the dissemination and retrieval of information and knowledge resources is common practice in our society. The strong point of it is obviously the ease of access of information sources. Navigators and browser have been developed to search documents with the requested information and knowledge, or with documents which refer to people, organizations and information systems that may help to solve one's information needs (cf. Schwartz (ed.), 2000). The problem, though, is not the lack of supply of documents, but the size of supply. This size makes it difficult to substantively match supply with specific information needs. Navigators and browsers may help to cope with the number of the documents, but are poor media when evaluating the relevance of the retrieved documents in the context of personal semantics and use values. An important cause for this problem is the difficulty of representing a knowledge "buyer's" needs completely and unambiguously.

When the information need is explicit and unambiguous, queries can be formulated which hit the desired items.

Material published as part of this proceedings, either on-line or in print, is copyrighted by the author with permission granted to the publisher of Informing Science for this printing. Permission to make digital or paper copy of part or all of these works for personal or classroom use is granted without fee provided that the copies are not made or distributed for profit or commercial advantage AND that copies 1) bear this notice in full and 2) give the full citation on the first page. It is permissible to abstract these works so long as credit is given. To copy in all other cases or to republish or to post on a server or to redistribute to lists requires specific permission from the author.
When the information need can be well anticipated, information products can be specified to be produced and delivered on specified moments to information buyers (cf. Meyer \& Zack, 1997). When the information needs are incompletely defined and ambiguous (both identify an implicit information need), the chance of a good hit is unlikely in a first attempt. Consequently, multiple searches are required to improve the specification of information needs. Several feedback procedures have been proposed to improve the semantic and actionable relevance of information items in implicitly specified information product situations (Spink, 1997). These procedures, though, do not solve any semantic problem, and the chance of missing an important hit when people use different meanings with the same words (homonyms) or use different words for the same meanings (synonyms) may still be very high. The required synchronization of meaning and intent among people can be realized through socialization in networks (Nonaka, 1994), through standardization via a superior authority in hierarchies (cf. Mintzberg, 1983), or through reference to a standard or source whose meaning has become common knowledge as a consequence of market power (cf. Hamel \& Prahalad, 1994).

From this understanding of information goods supply and demand mismatch problems, we aim at the definition of services on an Internet, which may help to match supply and demand of information at an information market. These services should be attuned to characteristics of these markets, which may be classified as pure markets, networks and hierarchies (cf. Boisot, 1998; Ciborra, 1987; 
Ouchi, 1980; Williamson, 1991). (Boisot (1998: 127) also identifies fiefs, which are informal systems under hierarchical control of a person, and thus combines some network and hierarchy characteristics. Williamson prefers the term hybrid instead of network.) Though this classification of markets is not new, its application to Internet information goods for the definition of design variables for information goods exchange services is new.

The approach adopted here is that of information markets consisting of information suppliers, information market services, and information buyers. Services can be provided to reduce search costs, transaction costs, and to increase transaction value (Gurbaxani \& Wang, 1991), but the parameters that make up such information market services are not yet known. Additionally, different kind of services may be needed for different information products and different information markets. An analysis of these differences is needed to assess the effectiveness of services proposed. The major question in this study therefore is:

\section{What design parameters constitute effective services for Internet information markets?}

To answer this question, we want to:

- Identify parameters of information markets, and categorize information services in these markets.
- Identify actors, processes, resources, and information flows of different information market services.

\section{An Analysis of Information Markets}

Information markets, like any market, consist of minimally one supplier and minimally one buyer. In the pure market type the number of buyers and suppliers is very large, in others this number may be moderate (networks) and in hierarchies this number may be very small. An important reason for this number is the type of information good to be traded. In pure information markets, like in other pure markets, the information good must be comparable to a commodity. Information goods though often require intense interactions and communications to be understood (networks), or are very specific to conform to a client's need (hierarchy). The importance of information in maintaining hierarchical and market power by information asymmetry (Douma \& Scheuder, 1991) requires a very strict information ownership. Following Picot et al (1997), four types of ownership can be identified: (1) the right of use, (2) the right of changing forms and structure of the transferred good, (3) the right to reap the profits of the good, and (4) the right to sell the good. For pure markets the right to sell is fundamental. In networks the sharing of information is emphasized as an important asset for the network's creative success (Liebeskind et al, 1996), implying group shared use rights. Because information markets

\begin{tabular}{|c|c|c|c|}
\hline & \multicolumn{3}{|l|}{ Market type } \\
\hline & $\begin{array}{l}\text { Pure information mar- } \\
\text { ket }\end{array}$ & Network information market & $\begin{array}{l}\text { Hierarchical information } \\
\text { market }\end{array}$ \\
\hline $\begin{array}{l}\text { Number of ac- } \\
\text { tors }\end{array}$ & Many & Several & Few \\
\hline $\begin{array}{l}\text { Type of information } \\
\text { good }\end{array}$ & Information commodities & $\begin{array}{l}\text { Heterogeneous professional } \\
\text { information and self- } \\
\text { representing information }\end{array}$ & $\begin{array}{l}\text { Strategic information and non- } \\
\text { tradable operational } \\
\text { management information }\end{array}$ \\
\hline $\begin{array}{l}\text { Ownership of in- } \\
\text { formation }\end{array}$ & Right to sell & $\begin{array}{l}\text { Right to use is shared in the } \\
\text { group }\end{array}$ & Right to reap profits \\
\hline Price mechanism & Invisible hand & Handshaking within network & Visible hand \\
\hline Services & Brokers & Coordinators & Expertise centers \\
\hline
\end{tabular}

Table 1: Information Market Parameters 


\section{Models of Information Markets}

implicate the transfer of information from a supplier to a buyer, the market actors arrange some kind of payment. This price mechanism may consist of an invisible hand (the pure market), mutual understanding and networking (the handshaking in networks) and the visible hand in hierarchies. Because prices are hard to define in networks (Liebeskind et al, 1996), the payment for use mostly consist of invitations for collaboration on further development, and sharing profits when the information good can be sold or exploited. In the hierarchy, the most important ownership is the right to reap the profits exclusively. The sales value (right of liquidation) may be less relevant because the information in hierarchies is highly asset specific and thus it is hard to sell (Williamson, 1991). To improve the efficiency and effectiveness of the information markets, several services are needed, consisting of infrastructures, applications, and commercial actors that help supply and demand to meet (brokers in pure markets), coordinators who help to shake hands in networks, and expertise centers that formally institutionalize information supplies in the hierarchy. Table 1 gives a summary of the market parameters thus identified.

These three market types will be further described.

\section{Pure Information Markets}

\section{Many market actors and information commodities}

Pure information markets have many actors supplying similar information, but two different kinds of information commodities:

1. Homogeneous information commodities. These commodities consist of clearly identifiable information products, though many similar and competing products exist, which can be supplied by many, and which may be of interest to many actors. This is the case of books and CD-ROMs.

2. Data products. Many press and news agencies supply similar information about events, which may be delivered in smaller data packages, but often consists of continuously updated deliveries. In comparison to homogeneous commodities, these data products are more flexible in shape and may have larger opportunities of meeting specific information needs. This can be realized by giving the buyer the opportunity of specifying his/her information need. Examples of this kind are the electronic publishing and market information services (cf. Nielsen).

\section{Ownership: Sales property rights}

Although copyright policies may be an important measure to enable any profit in information markets, they are often ineffective. The reasons for this are the following:

1. Low costs of reproduction and the principle of giveaway-and-still-have-it. In contrast to buying i.e. a car, a copy machine or printer may be sufficient to make an extra copy of an information commodity.

2. Inspecting and transfer are the same. In material goods markets, a buyer may experience every user experience before buying the product, but will lose the experience when the product is not bought. Homogeneous information commodities are less sensitive to this problem, because they have a value also after the product experience (e.g. for documentation, retrieval and status). Data products, though, consist of data that are relevant at a certain moment and become obsolete after their experience. This means that payment will have to be done in advance of access to the data.

\section{Price mechanism: Invisible hand}

Although author reputation is an important determinant of price and sales volume, buyers are confronted with a large number of alternative (homogeneous) information commodities. This implies that the price is based on the working of an invisible hand. For data products this is less the case. Although there are alternative suppliers of data products, the most value is created by an effective relationship with the supplier, so that the potential information resources can be attuned to specific buyer needs. The homogeneous commodity requires a single buying situation, and the data products require recurrent buying by a subscription.

\section{Services: Brokers}

Even pure markets consist of more than suppliers and buyers alone. They require transportation services (i.e. roads and logistic services) and transaction services (i.e. banks). Information market brokers do not own knowledge contents, but know about supply and demand. Two types of brokers exist: 
1. Shops, which sell homogeneous information commodities. An interesting and often cited example here is Amazon.com.

2. Information refineries, which sell data packs, mostly by subscription. These behave like a cafeteria in which a buyer can pick his issues of interest, but also can navigate and arrive in areas not planned in advance. Refineries also may supply the information requested by processing a client profile (Meyer \& Zack, 1996). People can submit their profile and interests via its cookies. An interesting example of an information refinery is CNN.com.

\section{Networks}

\section{Several market actors and professional information resources}

The nature of professional information complicates its price formation. Mostly the number of suppliers of this information is scarce, and the information often needs a high level of customization. Consequently the price is more the result of negotiation among known actors or professional ethics, and established by handshaking. Less customized than professional information, but even as important in networks, is the provision of self-representing information, which helps professional suppliers and buyers to find each other and to realize a possible information transaction.

\section{Ownership: Shared use rights}

The professional information product transfer thus does not automatically imply the right to change (norm is to invite the original idea producer to further collaboration), exploit the profits (norm is to share profits), and sell (it is hard to sell information which is the intellectual property of someone else, plagiarism is severely punished in professional societies). Professional associations and institutes service to define and guard these norms.

\section{Price mechanism: handshaking}

Professional information is mostly scarce, but among experts differentiation may exist among tariffs on condition of production costs (cf. dentists versus general practitioners) and scarcity of effectiveness (i.e. high hour rates for certain lawyers and low for others). To avoid excessive prices and low access of scarce services, the government may take action to impose tariff ceilings (esp. in medical field). To avoid too hard competition in an oligopolistic market (very few suppliers struggling for buyers), professional associations may try to impose minimum or standard tariffs (i.e. house brokers). The self-representing information has its value based on what people want to supply. High quality supply is hard to enforce, and top quality content providers often have not much time to put efforts in supply with uncertain and unknown returns (Wijnhoven, 1999).

\section{Services: Meeting realisers and Content services management}

The services that help to let supply and demand meet in networks are called coordinators. Two types of coordinators exist: (1) meeting realisers, who help experts to exchange information, and (2) Content services management, which help people to submit self-representing content and retrieve relevant resources.

An example of a meeting realiser is the Association for Information Systems (AIS). "The Association for Information Systems (AIS) founded in 1994, is a professional organization whose purpose is to serve as the premier global organization for academics specializing in Information Systems." (www.aisnet.org. p.1 quoted on October 12, 2000). AIS has over 2,700 members, and is an overarching association for other professional and academic associations. AIS publishes several documents and sponsors conferences and journals. The AIS web-site has a reference to $w$ ww.isworld.org, which is a resource for educators and researchers in the MIS field, and enables world-wide exchange of expertise.

An example of content services management is KPN Mobile's Intranet. To increase sharing of expertise and information within its organization, KPN Mobile developed an Intranet site. Appropriate documents put on this Intranet though are hard to find. This problem of supply and demand match has been approached by the use of LifeLink ${ }^{\circledR}$ software. KPN Mobile recognized that beside of Life Link software, several services are required, consisting of technical infrastructure management, application (Life Link) management, functional content independent management, content management, and information management, which consists of the definition of goals of the system for the organization.

The content and application management services consist of the following: 


\section{Models of Information Markets}

1. Manual filtering and clustering of new documents, and placing high importance documents for notification on the Intranet startup page.

2. Structuring of the user startup page according to KPN Mobile's predictable information needs.

3. Document use monitoring and feedback to information suppliers and buyers.

4. Personal profiles facilities to define personal queries, personal tasks, projects involved in, personal expertise.

\section{Hierarchy}

\section{Few market actors and asset specific information goods}

In hierarchical information markets the most important factor for non-tradability of information lies in its asset specificity, implying that:

1. Information given to people outside the hierarchy will not have any value for the receiver,

2. Or, information given to people outside the hierarchy will destroy the competitiveness of the original owner.

In the first situation we think of information given to a specific production facility, by which it is able to plan, monitor and improve effectiveness. Because production facilities may differ enormously, providing that information to another facility may be meaningless. In the second situation we think of strategic information, which can be very interesting for competitors. Hoarding this information causes an information asymmetry (Douma \& Schreuder, 1991), which is a major cause of strategic advantage. Related information types are strategic documents and specific $(\mathrm{R} \& \mathrm{D})$ knowledge of products, markets, and production performance. Business intelligence is an important method to reduce competitive information disadvantage.

\section{Ownership: Exploitation rights}

The distribution of strategic information must be well controlled and restricted. The right to modify and change is an obvious property of this information product, but most dominant are the strategic and operational exploitation rights. Some operational information may need the same distribution restrictions, though operational information may not make any sense outside the asset specific context of an operational process and thus its ownership control is not necessary.

\section{Price mechanism: Visible hand}

In hierarchies, the visible hand links supply and demand via fiat (Williamson, 1991). Similarly hierarchies create special units for business intelligence and allocate this information to specific decision-makers. Operational information supply and demand are organized via information systems and their design processes.

The price of strategic information is based on the subjective valuation of its opportunity to control some part of the business by creating information asymmetries. The price of operational information is based on its production costs and its contribution in operational decision-making.

\section{Services: Expertise centers}

Hierarchies have two types of expertise centers:

1. Information production departments, which are responsible for the availability and quality of the information supplies for operational processes. This often implies that information on human resources, production management, sales, and inventories have to be linked, to integrate use of all these resources. The information of these systems is nontradable, because each production environment will be specific. These information production centers are currently often supported by enterprise (resource planning) systems.

2. Specific organizational units that create information about the firm's environment and whose output is not freely available but requires specific access authority. These units are called business intelligence and may use external data sources from marketing research agencies (i.e. A.C. Nielsen, http://www.acnielsen.com and patent information publishers (i.e.

Www.Derwent.com (Bogner \& Thomas, 1994). They may include the opportunities of catching all kind of possibly important information and augmenting this information to relevant reports or information supplies for strategic management. The interpretation of these data requires extensive knowledge of strategic policies and the information needs of the strategic managers, or the delivery of facilities for strategic managers to define their own information needs and retrieve relevant data from databases (Westney \& Goshell, 1994). 


\begin{tabular}{|c|c|c|c|c|c|c|c|}
\hline & & \multicolumn{6}{|c|}{ Information products } \\
\hline & & \multicolumn{2}{|c|}{ Information commodities } & \multicolumn{2}{|c|}{ Professional resources } & \multicolumn{2}{|c|}{ Asset specific information } \\
\hline & & 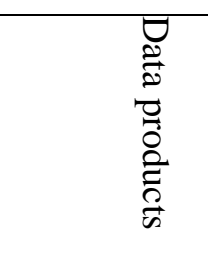 & 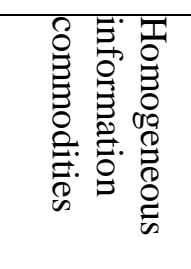 & 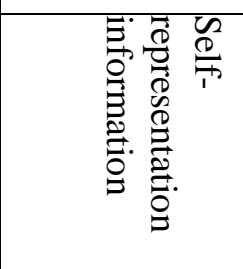 & 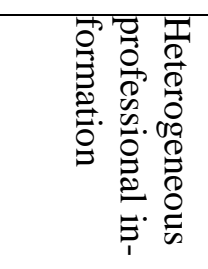 & 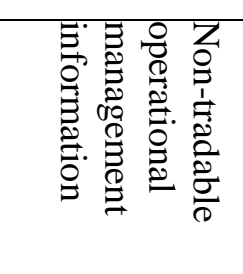 & 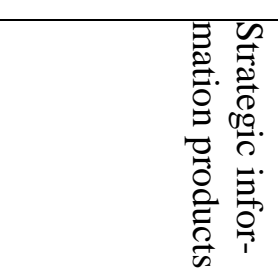 \\
\hline \multirow{6}{*}{ 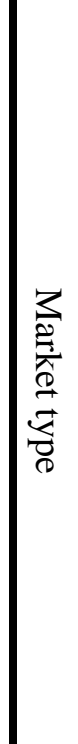 } & Pure & \multicolumn{2}{|c|}{ Brokers } & & & & \\
\hline & & $\begin{array}{l}\text { Information } \\
\text { refineries }\end{array}$ & Shops & & & & \\
\hline & Network & & & \multicolumn{2}{|c|}{ Coordinators } & & \\
\hline & & & & $\begin{array}{l}\text { Content ser- } \\
\text { vice } \\
\text { management }\end{array}$ & Meetings & & \\
\hline & Hierarchy & & & & & Expe & se centers \\
\hline & & & & & & $\begin{array}{l}\text { Management } \\
\text { information } \\
\text { production } \\
\text { center }\end{array}$ & $\begin{array}{l}\text { Business intelli- } \\
\text { gence center }\end{array}$ \\
\hline
\end{tabular}

Table 2: Summary of Market Services

\section{Summary of information market services}

Following the previous arguments, we have identified two information market services for each market type. A summary of these insights is given in table 2 .

\section{Design parameters of information market services}

In the design of information markets, we have to cope with several problems:

1. Many types of information goods exist and their nature makes certain market types more effective (realizing a transaction) and efficient (with minimal efforts) than others. In total we identified six information products: data products, homogeneous information commodities, self-representing information, heterogeneous professional information, nontradable operational management information, and strategic information products.

2. These information products have certain opportunities and limitations of transferring their ownership, particularly the use, exploitation and sales values. These values may be concentrated at one location or easily distributed among several owners.

3. Because of the nature of the information product and the related property right, only many or a few actors will be involved in the information market. 


\section{Models of Information Markets}

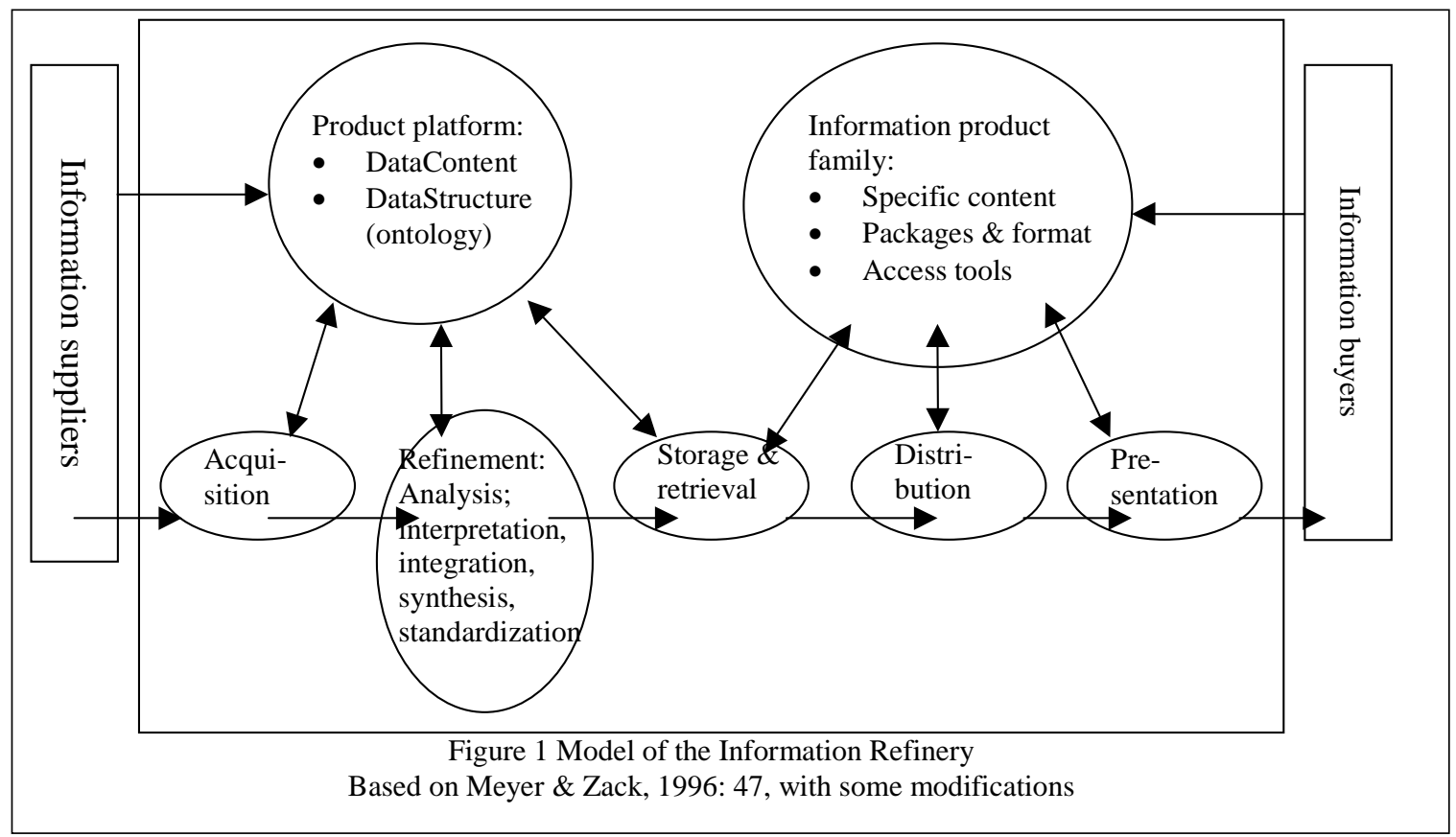

4. These actors, particularly the suppliers and buyers, need a certain level of semantic synchrony to understand the offerings and to realize buyer satisfaction.

5. Type of good, number of actors, type of property right transferred, and level of semantic synchronization determines the best type of information market needed.

6. These information markets require services (IT-based or human) to ease transaction.

The sixth issue will be further elaborated here by describing information market services models, applying the idea that each market service consists of suppliers and buyers, information resources, activities, and information flows, and process controls (Wijnhoven, 1998). We apply the following diagram objects to consistently draw these models. A box represents supplier and buyer. The left box refers to the supplier. The right box refers to the buyer. The market service is the actor between buyer and supplier and is referred at the highest level by a large box, but at the lower level by resources, activities, information flows, and controls. An ellipse represents an activity. A circle represents a resource (store of information or processing capacity). A two-tailed arrow represents a control, where the upper resource is the controller and the lower resource or activity is controlled. A horizontal arrow represents an information flow.

The actual information flow diagrams are given with the services as focal unit below.

\section{A model of an Information Refinery}

This archetype shows the different stages the information can be from initial supplier delivery till final presentation to the client. The product platform manages the information resources such that they can be easily produced to a pre-specified information product, or to facilities for buyers to easily create their own information product. The information product family provides facilities for buyers to pick the data products in the shape they want. The information supplier delivers elementary data to the acquisition activity of the service, and helps to fill the structure and content of the product platform. The buyer receives information packages, and submits information needs specifications to the access tools and information product family resource. Information refineries have product platforms and information product families containing the management models for the control of the information flow from initial acquisition to the presentation to the buyer. See figure 1 for a diagram of the information refinery.

\section{A model of an Information Shop}

Library systems and commercial e-book stores are examples of homogeneous information commodity shops. In the era of electronic commerce and e-publishing a merger of library and bookstores is likely. Basically the information commodities of an information shop go through five stages: 


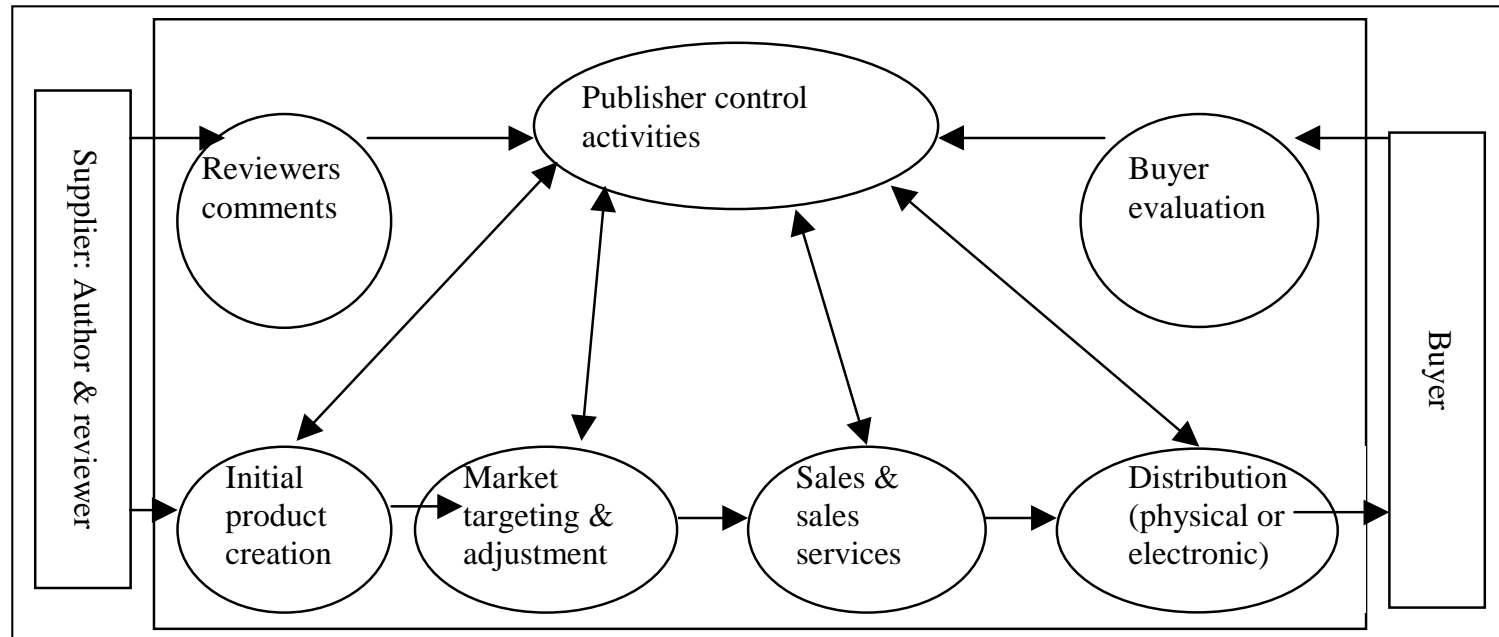

Figure 2: A model of the Information Shop

1. Initial product creation. This is the writing of books, software, and videos etc.

2. Publisher activities. The publisher adds his market expertise to the product, and the author may adjust the initial product accordingly. The publisher may use the comments of potential readers and experts to evaluate the initial product.

3. Sales via the shop. The shop may deliver extra information for potential buyers, like summaries, reviews, news and discussion groups around the product, and give links to related resources and products.

4. Distribution, via physical or electronic means.

5. Buyer reading and evaluation. The buyer may submit comments and reviews to the shop system, which may

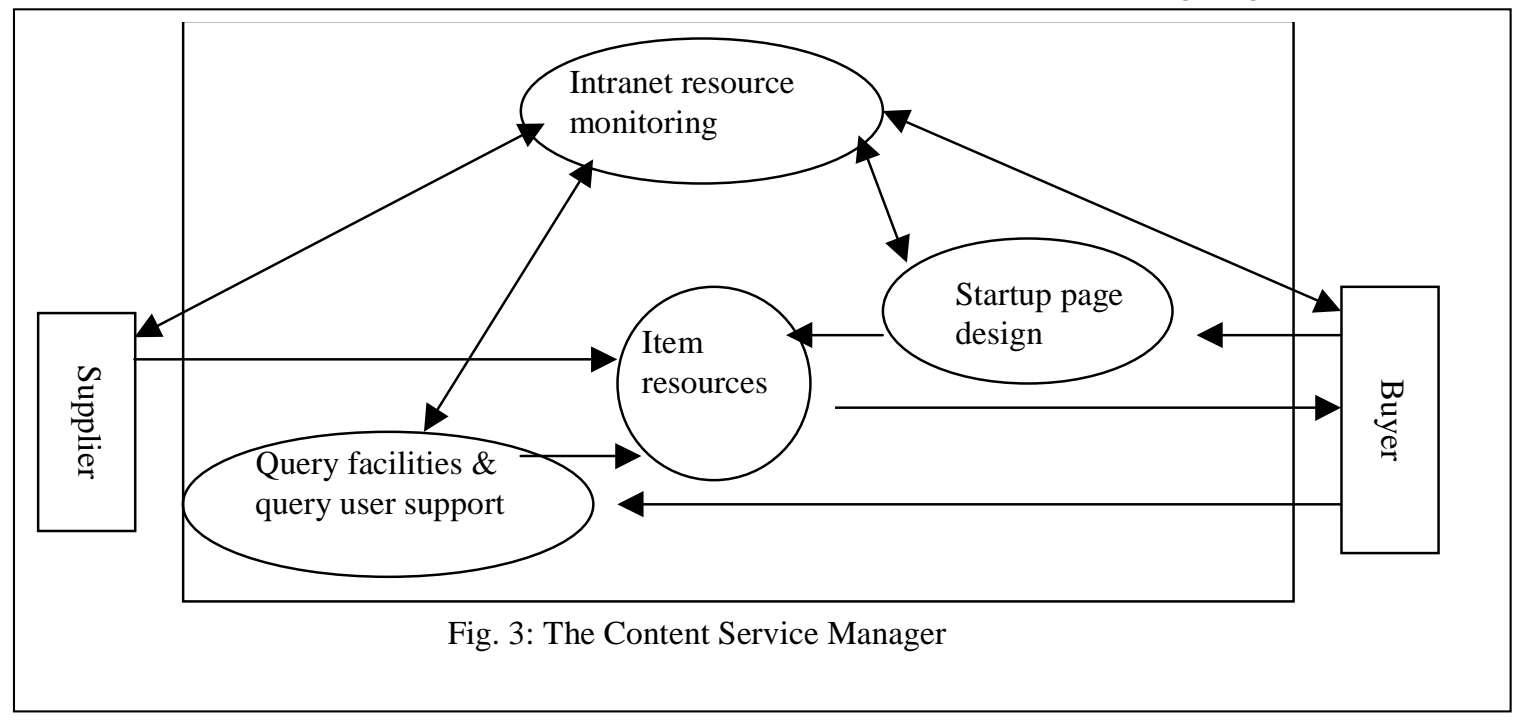

be a source for further development of the product.

Publisher expertise and resources control the activities of the information shop. These control activities are strongly based on commercial information gained from buyers, and quality information gained from reviewers. Figure 2 gives a diagram of the information shop.

\section{A model of a Content Service Manager}

To solve the many problems of receiving high quality Internet output and optimized supply utilization, the content service manager delivers the following services:

1. Start up pages, on basis of an understanding of high and repetitive user needs and related high quality supply.

2. Internet monitoring to give feedback to user needs and 


\section{Models of Information Markets}

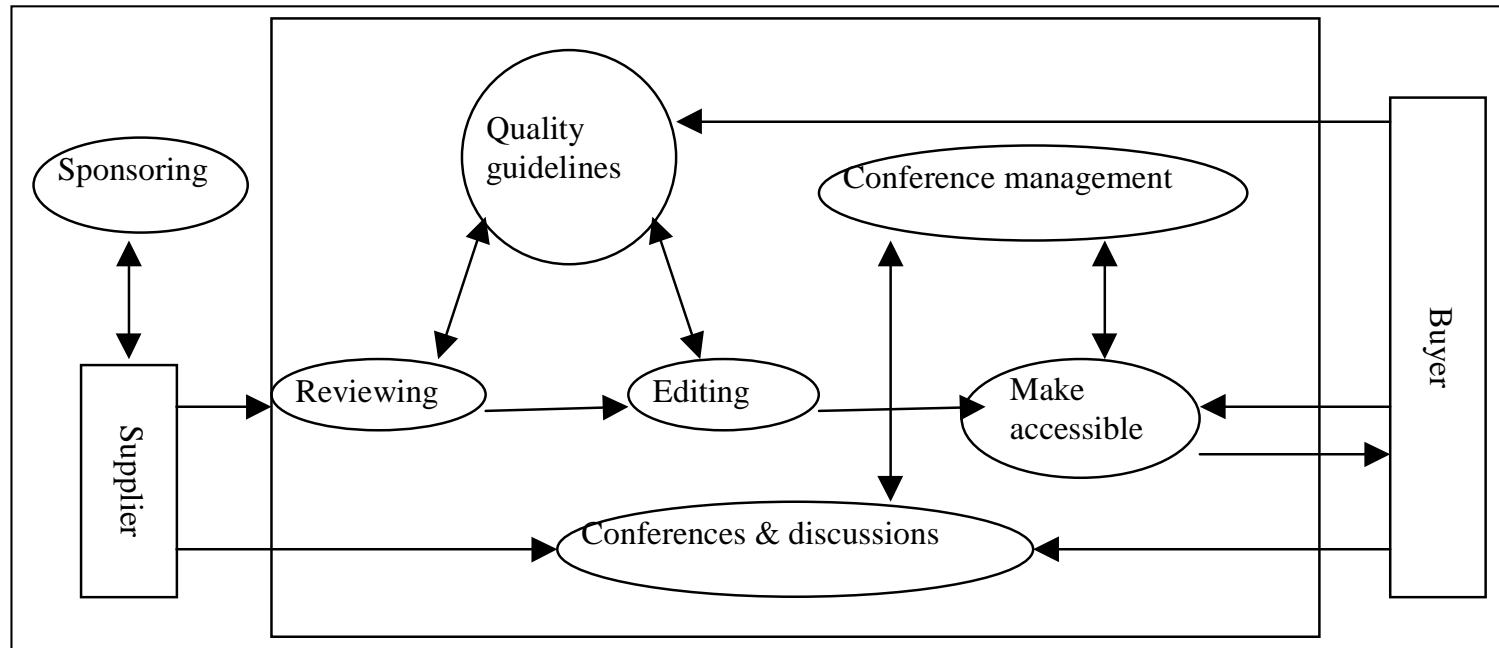

Fig. 4: The Meeting Realizer

supply intentions.

3. Query facilities (technical tools, including personal profile and query feedback software and user support).

\section{A model of a Meeting Realiser}

The meetings are facilitated by three means:

1. Publication policies (esp. quality guidelines) control the quality of content submitted to buyers at meetings.

2. Publication goes through four stages: sponsoring (someone has to give resources to an author), reviewing, editing, making accessible to buyers. The buyer accesses the content via search (information pull) or via automatic reporting (information push).

3. Informal information exchange, in physical or virtual ways (conferences and discussion lists). The confer- ence manager controls this process.

A diagram of the meeting realiser is given in figure 4 .

\section{A model of a Management Information Production Center}

The management information production center performs the following activities:

1. Catching user needs and converting these to information processing systems.

2. Development of the organization and registration of data from suppliers.

3. The development of programs to retrieve and augment these data.

4. The maintenance of this system controls that the re-

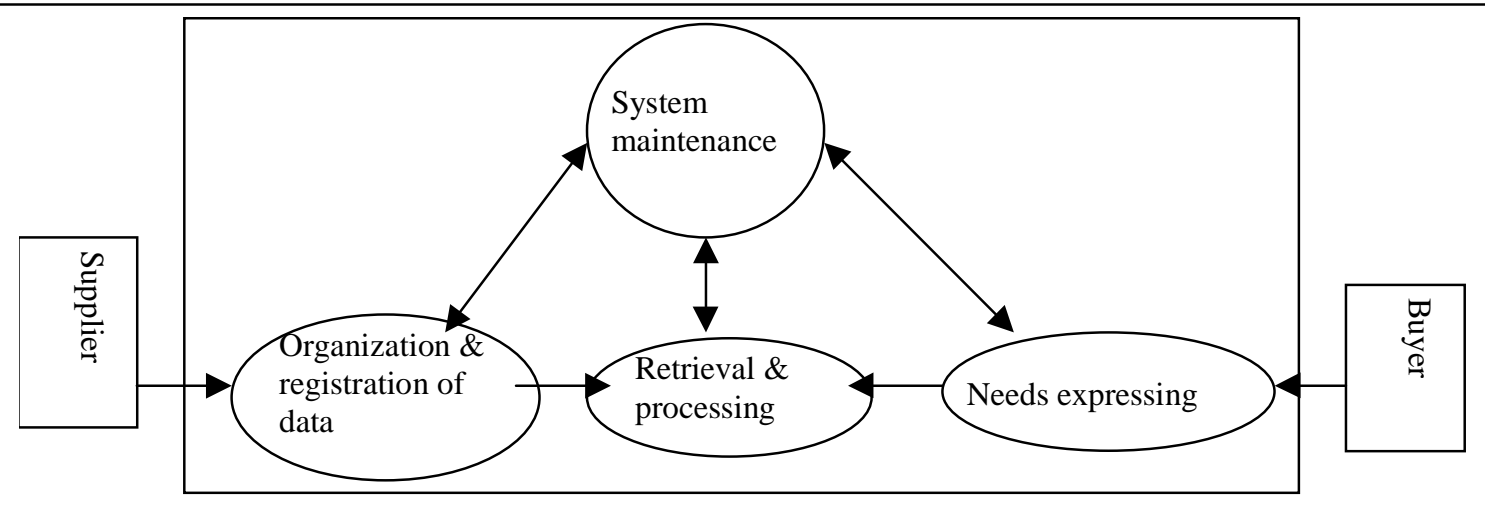

Fig. 5: The Management Information Production Center 
sources stay in line with changing buyer needs.

Figure 5 gives a diagram of a management information production center.

\section{A model of a Business Intelligence Center}

The business intelligence center provides several activities to reduce senselessness for strategic management information buyers:

1. Providing an information space for different (internal) information suppliers.

2. Providing executive information systems, for flexibly analyzing the resources of the management information production center.

3. Conducting market research to create information from external sources.

4. Providing meetings to exchange informally with potential sources.

5. Contracting internal or external experts to consult in the interpretation of data gained from the information space and market research.

These activities result in the diagram of figure 6 .

\section{Evaluation, discussion and conclusion}

This article started with the statement that technical means like browsers, navigators, and electronic catalogues, are insufficient to solve the semantically rooted problems related to supplier-buyer relations in information markets. Minimally six information goods are distinguished, two for each market type. These markets provide several services to help supplier and buyer to come to a transaction, which

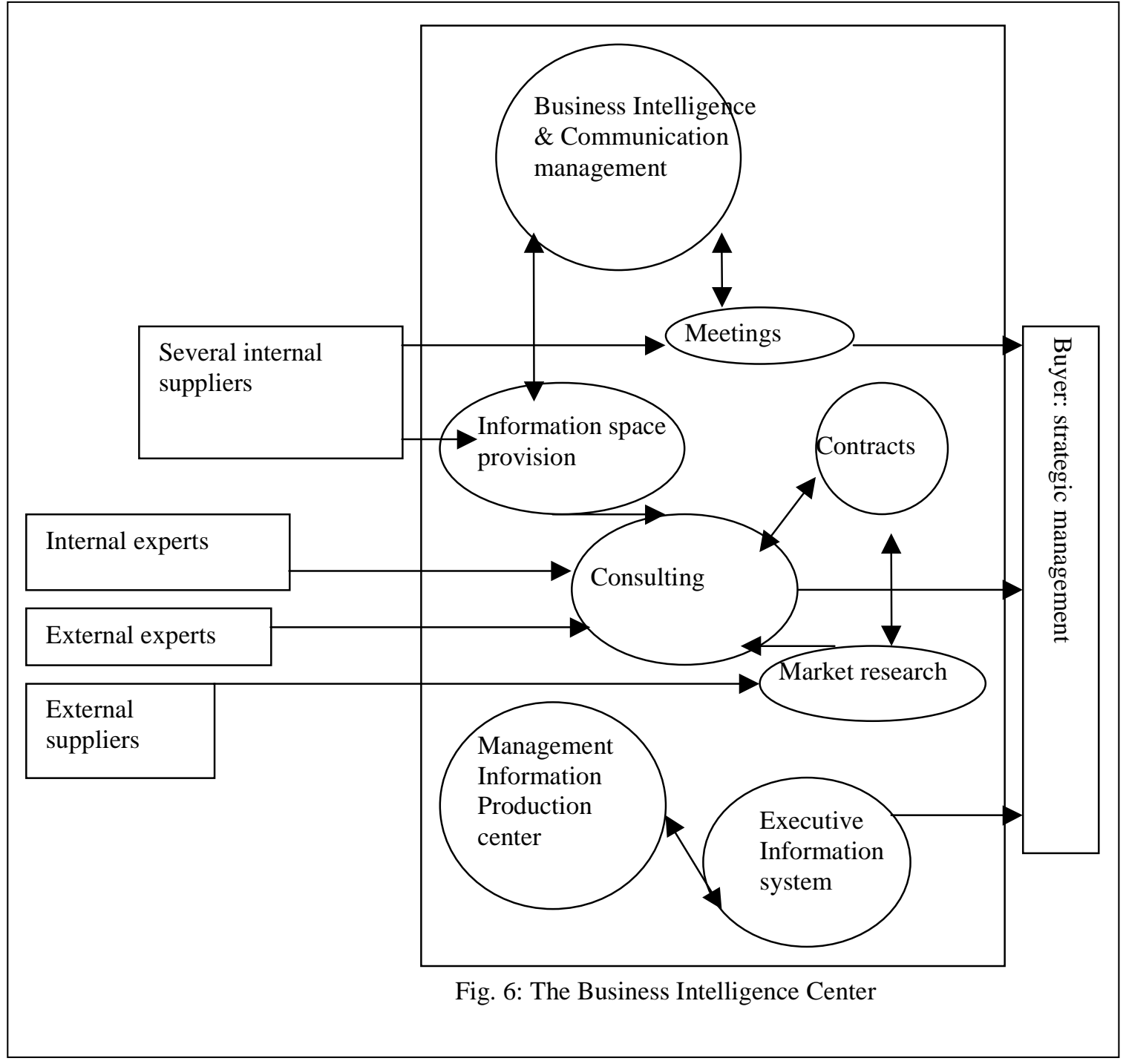




\section{Models of Information Markets}

pre-supposes some interactions (like information goods presentation and delivery customization via query tools) of supplier and buyer to synchronize semantics. These services are further analyzed to detect possible general features, which make up the information market services models. These models may be used to improve quality and the efficiency of the information market development processes. As such the article gives an answer to the general research question of what parameters constitute effective services in information markets. These parameters are summarized as information market parameters (number of actors, type of good, property right transferred, and price mechanism), and information market services and their parameters (configurations of suppliers and buyers, service controls, information flows, activities, and resources) (see tables 1 and 2 and the models). It appeared that browsers and navigators are just a few examples of a much larger collection of elements to build up information market services, and with extra facilities to improve supplier-buyer semantic synchronization. This gives an important context to the research in the field of Internets (cf. Schwartz, 2000).

However, there are some fundamental limitations to this study:

1. Though for each market type different services are detected, we do not yet have the theoretical maturity to check the completeness of possible services. Further exploration in the theory of information economics and markets may be welcome here.

2. No design method or workbreakdown structure has been given for information services development. The development of such a methodology may be welcome to put the concepts presented here into practice by realizing more detailed designs. Anticipating on this practical use, we expect that often a combination of services will be needed to solve a practical problem perception, resulting in configurations of services.

3. It may be important from an academic and professional viewpoint, if the ambitions of semantic synchrony problems reduction and improved design efficiency are actually achieved. This is worth another study.

This study also may be a fruitful extension of electronic commerce, which at the moment mainly is occupied with very rigidly defined commodities, and has problems of coping with the less precise nature of information commodities and data products.
This article was not intended to describe the practice of the integration of economic, organizational, and information technological elements of information markets. The article's contribution is in a framework for analysis, and a classification of services for design purposes. The actual realization of these concepts requires a further understanding of the actors involved, and thus a further breaking up of the black boxes of suppliers and buyers. Finally, the practice with these concepts will lead to further understanding of the project activities and management problems in realizing and exploiting information markets.

\section{References}

Bogner, W.C. \& H. Thomas (1994), Core competence and competitive advantage: A model and illustrative evidence from the pharmaceutical industry. In: Hamel, G. and A. Heene (eds.), CompetenceBased Competition. Chichester etc.: John Wiley \& Sons: 111-147.

Boisot, M. H. (1998), Knowledge Assets: Securing Competitive Advantage in the Information Economy. Oxford [etc.]: Oxford University Press.

Ciborra, C. U. (1987), Research agenda for a transaction costs approach to information systems. Boland, R.J. \& R.A. Hirschheim, Critical Issues in Information Systems Research, Wiley: 253-274.

Douma, S. \& H. Schreuder (1991), Economic Approaches to Organizations. New York: Prentice-Hall.

Gurbuxani, V. \& S. Whang (1991), The Impact of information systems on organizations and markets. Communications of the ACM, 34 (1): 59-73.

Hamel, G. \& C. Prahalad (1994), Competing for the Future. Boston (MA): Harvard Business School Press.

Liebeskind, J.L., A.L. Oliver, L. Zucker, \& M. Brewer (1996). Social networks, learning, and flexibility: Sourcing scientific knowledge in new biotechnology firms. Organization Science, 7 (4): 428-443.

Meyer, M. H. \& M. H. Zack (1996), The design and development of information products. Sloan Management Review, 37 (3): 43-59.

Mintzberg, H. (1983), Structures in Fives: Designing Effective Organizations. Englewood Cliffs (NJ), Prentice-Hall.

Nonaka, I. (1994), A dynamic theory of organizational knowledge creation, Organizational Science, 5 (1): 14-37.

Ouchi, W.G. (1980), Markets, bureaucracies, and clans. Administrative Science Quarterly, 25 (March, 1980): 129-141.

Schwartz, D. G., M. Divitini, \& T. Brasethvik (eds.) (2000), Inter-based Organizational Memory and Knowledge Management. Hershey (Pa): Idea Group Pub. 


\section{Wijnhoven}

Spink, A. (1997), A study of interactive feedback during mediated information retrieval. Journal of the American Society for Information Science, 48 (5): 382-394.

Westney, D. E. \& S. Ghoshal (1994), Building a competitor intelligence organization: Adding value in an information function. In: Allen, T. J. \& M. S. Scott Morton (eds.), Information Technology and the Corporation of the 1990s: Research Studies: 430-453. New York: Oxford University Press.

Wijnhoven, F. (1998), Knowledge logistics in business contexts: Analyzing and diagnosing knowledge sharing by logistics concepts. Knowledge and Process Management, 5 (3):143-157.
Williamson, O. E. (1991), Comparative economic organization: The analysis of discrete structural alternatives. Administrative Science Quarterly, 36 (1991): 269-196.

\section{Biography}

Fons Wijnhoven is a faculty member of the University of Twente, School of Technology \& Management, where he teaches knowledge management and IT and organizational change. Prof. Wijnhoven has authored three books and several articles on knowledge management, organizational memory systems, and IT impact on organization. 